\section{Rare ruptured pulmonary arteriovenous malformation mimicking lung tumor in a girl}

A 17-year-old girl presented to our institution with sudden onset of dyspnea for one day. Her laboratory results revealed white blood cells $11.54 \times 10^{9} / \mathrm{L}$ and hemoglobin $57 \mathrm{~g} / \mathrm{L}$. Chest radiograph demonstrated a large left pleural effusion with a suspicion of a lung tumor. A chest tube was inserted, and $800 \mathrm{~mL}$ of hemorrhagic effusion was removed. Video-assisted thoracoscopic surgery (VATS) was performed, and a large mass was visible (Fig. 1a). A biopsy was performed, demonstrating reactive mesothelial hyperplasia. Contrast-enhanced computed tomography (CT) was performed later and revealed pulmonary arteriovenous malformation (PAVM) (Fig. 1b, 1c). Pulmonary angiogram confirmed a ruptured PAVM with a large feeding artery measuring $14 \mathrm{~mm}$ in diameter, which was successfully embolized using a $20 \mathrm{~mm}$ Amplatzer Vascular Plug (Fig. 1d, 1e and Videos 1-4). She made an excellent recovery immediately and during the six-month follow-up.

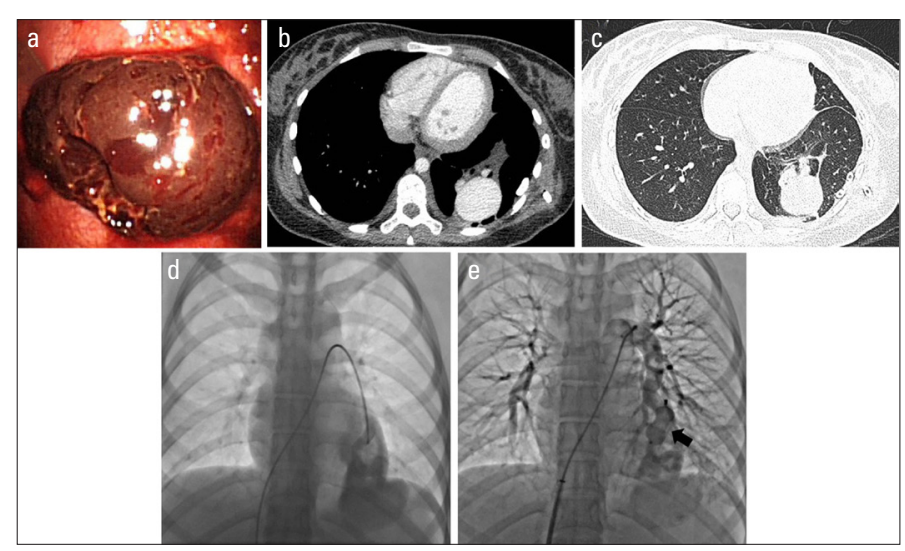

Figure 1. (a) Thoracoscopic view showing a large mass in the left lower lobe. (b, c) Contrast-enhanced computed tomography revealing pulmonary arteriovenous malformation (PAVM). (d) Pulmonary angiogram confirming ruptured PAVM. (e) Pulmonary angiogram showing PAVM embolization with a $20 \mathrm{~mm}$ Amplatzer vascular plug (black arrow)
PAVM is a structurally abnormal vascular connection between pulmonary arteries and veins. The incidence of ruptured PAVM varies from $2 \%$ to $8 \%$. Hemothorax is rare when presenting as the initial symptom of PAVM. It frequently occurs in patients with coagulopathy, pregnancy, or during an air flight. However, our patient had none of the above history. VATS initially misdiagnosed her as having a lung tumor because of the presence of active bleeding and numerous clots. Contrast-enhanced CT is preferred in detecting PAVM. In case of rupture, percutaneous embolization should be performed emergently. Plug and occluder embolization was preferred over surgical resection when managing the PAVM in the peripheric location with a solitary and large feeding artery.

Informed consent: Informed consent was obtained from all individual participants enrolled in the study.

Video 1. Selective pulmonary angiography showing a giant pulmonary arteriovenous malformation with a solitary and large feeding artery

Video 2. After inserting a hydrophilic guidewire and a $5 \mathrm{~F}$ multipurpose catheter into the nidus part of the pulmonary arteriovenous malformation, a $9 \mathrm{~F}$ atrial septal defect sheath was advanced easily into the feeding artery over the multipurpose catheter

Video 3. A $20 \mathrm{~mm}$ Amplatzer vascular plug was implanted in the feeding artery to embolize the pulmonary arteriovenous malformation

Video 4. The plug was released, and pulmonary angiography showed a significant decrease of blood flow into the pulmonary arteriovenous malformation

\section{Suxuan Liu (D), Xudong Xu (D), Yongwen Qin (D), Xianxian Zhao (D) Department of Cardiology, Changhai Hospital; Shanghai-China}

Address for Correspondence: Suxuan Liu, MD,

Department of Cardiology, Changhai Hospital; Shanghai-China Phone: 00862131161263

E-mail: suxuan.liu@qq.com

(C) Copyright 2021 by Turkish Society of Cardiology -

Available online at

www.anatolicardiol.com

D0I:10.5152/AnatolJCardiol.2021.74790 